\title{
Using Game Theory to Understand Screening for Domestic Violence Under the TANF Family Violence Option
}

\author{
Soonok An \\ Jisung Yoo \\ Larry G. Nackerud
}

\begin{abstract}
Universal screening for domestic violence in the Temporary Assistance for Needy Families (TANF) program is required by most states, but its implementation is questionable. This paper employs game theory to conceptualize interactions between TANF applicants and frontline eligibility caseworkers. The intended outcomes of universal screening for intimate partner violence (IPV) - granting of a good cause waiver to IPV victims - are valid only by the assumption that caseworkers perform their roles. To grant a good cause waiver, TANF applicants and caseworkers should exchange two types of information: 1) disclosure of abuse by IPV victims and 2) notification of the availability of good cause waivers by caseworkers. This paper illuminates that intended outcomes of universal screening for IPV are difficult to achieve and discusses the applicability and limitations of game theory for policy evaluation.
\end{abstract}

Keywords: Universal screening for intimate partner violence, strategic game theory, Family Violence Option, policy analysis

The Family Violence Option (FVO) enacted during the 1996 welfare reform aims to assure safety for the person who experiences intimate partner violence (IPV) by mitigating any barriers to receiving and maintaining the cash benefits inherent in Temporary Assistance for Needy Families (TANF)(Casey, Davies, Gifford, \& Menard, 2010). Studies have found a higher prevalence of IPV in welfare populations compared to the general population (Lawrence, 2002; Meisel, Chandler, \& Rienzi, 2003). Among TANF enrollees, the prevalence of IPV ranged from $14 \%$ to $32 \%$ for the previous 12 months (Gallagher, 2011; Tolman \& Rosen, 2001). TANF recipients who had experienced IPV had multiple barriers to meeting TANF requirements, such as mental and physical problems, housing instability, human capital deficits, and child-related problems, with 2.3 barriers on average (Brush, 2004). Such individual barriers elevate the risk of program sanctions (Casey, 2010).

The service goals derived from the FVO are clear. The FVO may provide such support services as (1) waivers to TANF requirements, for example, work responsibility, lifetime limits, and/or child support enforcement; and (2) referrals to support services to address the needs of identified TANF applicants experiencing IPV (Government Accountability Office [GAO], 2005). To promote an informed use of waivers and other relevant services, the implementing agencies in at least 43 states have adopted a universal screening protocol (GAO, 2005). IPV screening during the TANF application and assessment process is designed to resemble IPV screening in health care settings that routinely assesses "current harm or risk for harm from family and IPV in asymptomatic persons” (Nelson, Nygren,

Soonok An (Corresponding author), PhD, School of Social Work, University of Georgia, 279 Williams Street, Athens, GA 30602-7016, Phone: (706) 424-1470 / Fax: (706) 542-3364 /Email: aso@uga.edu. Jisung Yoo, MA, Department of Lifelong Education, Administration, and Policy, University of Georgia, 850 College Station Road, Athens, GA 30602, Phone: (706) 469-0887 /Email: jisyoo@uga.edu. Larry G. Nackerud, PhD, School of Social Work, University of Georgia, 279 Williams Street, Athens, GA 30602-7016, Phone: (706) 542-5470 / Fax: (706) 542-3364 /Email: nackerud@uga.edu. 
Mclnerney, \& Klein, 2013, p. 388). However, the IPV screening in a TANF program differs in that it also assesses barriers to compliance with program requirements due to IPV and ultimately may benefit TANF clients with such barriers.

Universal screening for IPV as a protocol embraces diverse behavioral strategies for TANF eligibility caseworkers and applicants. By routinely asking TANF applicants about their IPV experience, routine screening creates an opportunity for all applicants to disclose abuse (Davies, 2010). On the other hand, universal screening mandates that TANF eligibility caseworkers notify applicants that TANF requirements may be waived. Temporary waivers to TANF requirements for victims of IPV are referred to as "good cause” waivers (Cooke \& Burke, 2003). Notification of good cause allows applicants to make an informed decision to apply for a waiver (Pataki \& Doar, 2006). Thus, universal screening exchanges key information about IPV from an applicant to a caseworker, as well as information about good cause waivers from a caseworker to an applicant, through their choice of behaviors that incrementally support the outcome of waiver use. An assessment that opts out of either of the two conditions cannot be referred to as universal screening (DeCarli, 2001; Lindhorst \& Padgett, 2005).

Indeed, waivers for TANF requirements were so seldom an option for TANF applicants that a mere $2.4 \%$ of California cash assistance enrollees were waiver-holders in April 2013 (California Department of Social Services, 2013). The prevalence of IPV among TANF applicants in California and their need for good cause waivers are unclear, but lifetime prevalence of IPV among welfare recipients is as high as $80 \%$ (Meisel et al., 2003). Barriers to comply with work requirements were reported in $8.1 \%$ to $8.4 \%$ of randomly selected welfare recipients in two counties (Norris, Speiglman, \& Dasinger, 2002; Speiglman, Fujiwara, Norris, \& Green, 1999). Other studies reported even lower waiver rates (Hetling, 2011; Lindhorst, Casey, \& Meyers, 2010). Low rates of waivers are inevitably linked to identification and notification rates. An interview study revealed that screening rates ranged from $2.9 \%$ to $7.5 \%$ in three states, with Georgia as an outlier at 28.8\% (Lindhorst, Meyers, \& Casey, 2008). Nevertheless, the identification rate in all four states that had adopted the FVO was around $2 \%$. TANF applicants were also not informed of good cause waivers. In 2000, 56 to 72\% of TANF applicants in the state of New York did not receive an IPV screening form that described good cause (Hearn, 2000). In California, one-third of the disclosed applicants were not informed of their eligibility for IPV services (Spatz, Katz, \& Rees, 2005). Routine screening and notification were rarely implemented together, and only $1.2 \%$ of the eligibility caseworkers used both methods in Georgia, Michigan, New York, and Texas (Lindhorst et al., 2008). TANF caseworkers tended to identify applicants with IPV experience through profiling criteria, such as immediate danger, separation from an abuser, or subjective judgments (Hetling \& Born, 2006).

While IPV screening in TANF involves an interaction between caseworkers and applicants, only a few studies have attempted to describe how caseworkers and applicants interact with one another (Lindhorst \& Padgett, 2005), and none of the reviewed studies provided a theoretical or conceptual framework to identify factors that determine the success of IPV screening. If such a framework were available, it could be used to improve screening outcomes. 
This paper conceptualizes interactions between TANF applicants and frontline eligibility caseworkers for their IPV screening processes based on game theory. By choosing the most relevant game model to formalize IPV screening in TANF, this paper hypothesizes two game models with different scenarios of TANF applicants' informed and uninformed decisions for disclosing abuse. The scenarios represent TANF applicantcaseworker interactions under universal screening for IPV, as well as IPV screening that is not universally applied. The authors claim that the intended outcomes of universal screening for IPV are valid only through several assumptions. In addition, this paper compares the two game models on the basis of how a caseworker and an applicant interact. This paper is not intended to provide empirical findings based on this game theoretical conceptualization.

\section{Game Theory Application in the Context of IPV Screening in TANF}

This section provides the definition of game theory, major components of game theory, and potential contributions of game theory application in policy evaluation and in understanding IPV screening in TANF. Game theory is a useful and relevant policy evaluation tool that can be used to understand interactions between TANF applicants and frontline eligibility caseworkers during IPV screening. An application of game theory in this paper examines how good cause waivers can be granted to victims of IPV in TANF programs as intended by the Family Violence Option.

Game theory describes strategic interactions and explains the outcome of such interactions (Greif, 2006; Osborne, 2004). A human interaction is strategic when one chooses a behavior by anticipating another person's behavior. Thus, the behaviors of two actors are interrelated. Game theory establishes an analytic model that illuminates a problem or a social dilemma in the process of a particular interaction in a particular setting (Grief, 2006). Game theory has been applied to understand interactions in social science between an insurance company and the insured (Agee \& Gates, 2013; Dowd, 1982), a principal and an agent (Miller \& Whitford, 2002; Saam, 2007), parties to international relations (Field, 2014; Polachek \& Xiang, 2010), and a ruling party and the opposition party in Congress (Groseclose \& Milyo, 2013). The explanatory function is the key feature of game theory and is based on a rationality assumption. The assumption notes that a person will behave in certain ways to maximize gain and minimize loss.

A game is defined by particular components such as players, outcomes, strategies, rationality, and information (von Neumman \& Morgenstern, 1953). First, players are subjects of particular interactions and play a part to induce an outcome (Hermans, Cunningham, \& Slinger, 2014). Games within the context of game theory are played by two people, and/or between groups, and they are simultaneously or repeatedly played (Osborne, 2004). Second, an outcome is what players obtain at the end of the interactions and indicates the purpose of a game (Milton, 2006). Third, strategies refer to a possible set of behaviors or actions that each player can choose at one time. In a strategic situation, a player acts upon the other player's strategy; that is, players consider each other's strategies when making decisions. 
Fourth, a key assumption of game theory is that players are considered to be rational actors. This assumption consists of two properties: expected utility and a minimax criterion (von Neumann \& Morgenstern, 1953). On the one hand, rational behavior chooses an alternative among an exhaustive action set that maximizes a particular function called an expected utility. Giocoli (2006) defined expected utility as the rationality of a preference system. The rationality of a preference system endorses the subjective expected utility of a decision (Savage, 1954). On the other hand, a rational actor should follow the minimax criterion that refers to a strategy that minimizes loss due to the other player's choice (Giocoli, 2006).

Fifth, information indicates the players' knowledge of types of other players, their and the other players' possible strategies, strategies the other players choose, and/or preferences of the other players (Garratt, Troger, \& Zheng, 2009). In case of a perfect or complete game in which each player is aware of the actions chosen by the other player and also knows possible actions available to them, strategies are common knowledge to both players (Witzel, 2009). Conversely, incomplete information defines an incomplete game in which at least one player is somewhat uncertain about the other player's type (i.e., IPV victim or non-victim), strategies, and/or preferences (Harsanyi, 1987).

Game theory is relevant to policy evaluation for specific occasions. Game theory is particularly useful when information on how policy is implemented by the actors is unavailable or not easily accessible (Hermans et al., 2014). Many human interactions at the policy implementation level are hard to observe, thus limiting valid data with relevant variables. In fact, collection of primary data or access to secondary, administrative data of IPV screening from state and local TANF offices is often not available due to multi-level processes for permission, disinterest of the implementation of IPV screening in TANF, and/or distrust of outside researchers. Such data, including direct observation, were obtained in two research initiatives (Hetling \& Born, 2006; Hetling, 2011; Meyers \& Laurie, 2005). A very motivated TANF program (i.e., Maryland Department of Human Services) allowed outside researchers to analyze administrative data (Hetling, 2011; Hetling \& Born, 2006), and with collective research initiatives based on a federal level of funding and support (i.e., the U.S. Department of Health and Human Services) they could observe the applicant-caseworker interactions and interview the TANF workers (Meyers \& Laurie, 2005). Existing data also do not contain relevant variables to predict good cause waivers in relation to routine screening for IPV and routine notification of good cause waivers. Thus, we do not know whether universal screening for IPV is effective at identifying IPV victims and granting of waivers.

For evaluation of policy implementation, a well-developed theoretical framework to analyze available data is difficult to secure. Game theory helps simplify and clarify complex processes of interaction with certain game components. Although a game model cannot explain actual outcomes of the interaction, it can provide a logical structure to interpret observed human interactions and the variations of instances of interactions (Hermans et al., 2014), and/or it can also develop hypotheses for empirical testing with statistical methods. 
Game theory may be relevant to evaluation of intake interviews for welfare services. Like IPV screening in TANF, such intake interviews are involved in identifying eligibility and/or assessing need for services. Service providers may need to manage resources parsimoniously and identify eligible applicants for specific services - in this case, good cause waivers in IPV screening. This paper presents the potential applicability of game theoretical models as an evaluation method for social welfare policy--in this case, eligibility screening in TANF. The objective of this paper is to understand how intended outcomes to grant good cause waivers to IPV victims can be achieved.

\section{Bayesian Strategic Game Modeling}

This section addresses the relevance and applicability of Bayesian strategic game modeling to IPV screening in TANF and describes major components of (Bayesian) game theory to conceptualize IPV screening. The Bayesian strategic game is particularly relevant to modeling a strategic game under uncertainty (Osborne, 2004). This type of game is also called an incomplete game. IPV screening in TANF is an incomplete game in that the TANF applicant's experience with IPV is unknown to a TANF frontline eligibility caseworker. In a common two-person zero-sum game in which a player benefits only at the equal expense of others, a player attaches subjective probability weight to the other player's actions and beliefs. This type of decision process is called a Bayesian theorem (Keeney \& Nau, 2011; Savage, 1954). A Bayesian game model combines formal game theory and probability theory with set beliefs about a player's hidden or unknown type. IPV screening in TANF should identify applicants' hidden type regarding IPV experience through the interactions between an applicant and a caseworker.

The Bayesian strategic game is potentially applicable to conceptualize interactions that need to identify a hidden characteristic of a player. Service eligibility interviews seem suitable for model development with a Bayesian strategic game. IPV screening in TANF resembles a market of "lemons," where the good being exchanged possesses high quality variations that are unknown to the buyers (Akerlof, 1970). The market of TANF identifies variations of applicants' characteristics related to their eligibility for good cause waivers, but such identification processes may be unattractive to the buyers, who are TANF service providers. High variations in eligibility for good cause waivers embrace costs based on identifying applicants' experience with IPV. One major cost is from the sellers' potential dishonesty regarding their true characteristics, for example, applicants' false disclosure of IPV. Such risk is called adverse selection (Moe, 1984).

Bayesian strategic game modeling is also relevant to IPV screening in TANF because identification of one's eligibility is linked to specific rewards. The purpose of a game is to deliver a good cause waiver in IPV screening in TANF. Good cause for IPV victims waives one or a combination of the following TANF requirements: work responsibility, child support enforcement, and lifetime limits. Without the consideration of a good cause waiver, TANF recipients can receive TANF for only 48 months in their lifetime, and every adult TANF recipient should be involved in work or work activities on a weekly basis and identify the biological father of a child to apply for child support (GAO, 2005). Receiving a good cause waiver also avoids program sanction by the failure to comply with any of the program requirements and/or extending TANF for up to 60 months (Casey, 2010; Fontana, 
2000). In that case, good cause waivers may generate direct monetary rewards for IPV victims. A good cause waiver also avoids the risk of further abuse by complying with TANF requirements or recovery from the impact of abuse. These rewards may be attained within a more long-term timeline, yet it may be difficult to account for monetary rewards while a person is in the TANF program. A good cause waiver potentially prevents health costs from putting an IPV victim in danger through TANF requirements and/or perpetrating IPV. The waiver ultimately could strengthen its recipients' capacity as a workforce.

The potential rewards of receiving a good cause waiver are critically linked to the service need (Levin \& Zeisel, 2009; Tolman \& Rosen, 2001). The rationale for the Family Violence Option is that IPV victims on welfare tend to have more barriers to complying with TANF requirements (Tolman \& Rosen, 2001). Theoretically, IPV victims who enter the TANF program and have barriers to complying with TANF requirements would perceive good cause waivers as rewards. The same type of TANF applicants would not perceive rewards if they do not receive the waivers. The following seven game components may define IPV screening in TANF programs.

1. Players: The IPV screening in a TANF program is a two-person interaction between a TANF applicant and an eligibility caseworker.

2. Incomplete information: A TANF applicant and an eligibility caseworker make a decision with incomplete information. Incomplete information refers to the situation in which players may not know some information about the other players, such as their characteristics, strategies, etc. (Harsanyi, 1987). At the beginning of the IPV screening, a TANF eligibility caseworker does not know about a TANF applicant's characteristic as an IPV victim. In game theory, such a characteristic is called a type or a state (Osborne, 2004). Such a state is denoted as “ $\omega$ ”. Because not all applicants experience IPV, two states of $\omega_{1}$ (applicants with IPV experience) and $\omega_{2}$ (applicants without IPV experience) exist. On the other hand, a TANF applicant may not know about good cause waivers. As a caseworker does not know the status of IPV among TANF applicants, the caseworker may subsequently face the following situations: a TANF applicant should signal the state of IPV to a caseworker, and the caseworker formulates a belief which is the probability $0 \leq p \leq 1$ to each state of IPV of a TANF applicant consistent with the signal (Zamir, 2010).

3. Outcomes: The intended outcome of universal screening for IPV is to grant good cause waivers to applicants with IPV experience who have difficulty complying with a TANF requirement and to not grant good cause waivers to applicants without IPV experience.

4. Rationality: A TANF applicant and a TANF eligibility caseworker are rational actors who maximize the expected utility of the outcome, receiving or granting a good cause waiver (Milton, 2006; Nurmi, 2005). An expected utility function represents a player's preferences (Keeny \& Nau, 2011), and it is defined by both a single action profile such as disclose IPV and a state of a player's characteristic such as a true IPV victim. The term expected utility is interchangeably used with preferences or payoffs (Osborne, 2004). A rational 
TANF applicant who has difficulty complying with TANF requirements due to IPV will prefer receiving a good cause waiver to not receiving such a waiver. A rational TANF eligibility caseworker will provide a waiver to IPV victims who have difficulty complying with TANF requirements.

5. Preferences: Preferences can be ordered, and such order of preferences is called ordinal preferences (Barnett II, 2003). Ordinal preferences mean that if a player prefers action a to action b, and action b to action c, then that player prefers action a over action c. If a caseworker prefers granting a good cause waiver to not granting a good cause waiver to an applicant, a higher number is assigned to the strategy of granting a good cause waiver compared to the other strategy-for example, 2 for granting a good cause waiver and 1 for not granting a good cause waiver, simply because 2 is greater than 1 . Players choose their optimal strategy (action), the one most preferred in the strategy profiles, so that the outcomes furthest from that choice are the least preferred (Shepsle, 2010).

6. Strategies: A choice of a specific strategy is determined based on the expected utility of the final outcome. If TANF applicants expect a high utility to obtaining a waiver, they would strategically disclose IPV rather than not disclose IPV. A player chooses one of the strategies at the time of their decision node. IPV victims could disclose their experience with abuse at a TANF appointment or be silent.

7. $\underline{\text { Rules: }}$ IPV screening in TANF follows specific game rules. Game rules indicate all of the game components and they represent who moves, when they move, what options players have, what they know about the information, and why they move (associated with expected utility)(Matos, Ferreira, \& Andrade, 2010). In relation to the order of moves of decisions, a TANF applicant should disclose the experience with abuse prior to the caseworker's granting of a good cause waiver.

\section{Particular Assumptions for Hypothesizing Universal Screening}

This section begins with modeling universal screening for IPV according to the FVO using the Bayesian strategic game model. To explore how intended outcomes of IPV screening may come about, four additional assumptions may be required to conceptualize the TANF applicant-caseworker interactions within universal screening for IPV.

First, this paper assumes that the FVO defines rationality respectively for a TANF applicant and a caseworker. A rational TANF applicant would maximize expected utility regarding a good cause waiver. However, a rationality assumption for a caseworker needs clarification. In the real world, caseworkers may not perceive great utility by granting a waiver. Caseworkers' attitudes and beliefs about a victim's worthiness to receive TANF benefits influence their screening of IPV (Carrington, 2005; Lindhorst \& Padgett, 2005). However, in the hypothetical scenario of universal screening for IPV, a TANF caseworker is assumed to strategically perform universal IPV screening to grant a good cause waiver. A caseworker should perceive lower utility for granting a good cause waiver to a false IPV victim than granting it to a true IPV victim. 
Secondly, this paper assumes one exception from the rationality assumption of a TANF applicant: self-determination. A TANF applicant who is informed of good cause waivers may not disclose IPV if the applicant does not perceive the waiver as a reward. TANF applicants may still prefer to pursue work and receive child support instead of receiving temporary good cause waivers or exemptions from TANF requirements (GAO, 2005; Raphael \& Haennicke, 1999). Researchers found that victims of domestic violence did not use the waivers because they had no current danger, did not want to complete paperwork, had no evidence to prove harm, feared the abusive father, were motivated to work, and received child support from the father of their child (Fontana, 2000; Levin, 2001). This paper considers these conditions as self-determination. Social work values appreciate clients' self-determination to use or refuse services (National Association of Social Workers [NASW], 2008, 2013). Although a service provider may inform clients of opportunities and potential resources that could be used in a voluntary situation, the client is always the decision-maker.

The assumption of self-determination as an exception was added because IPV experience is a core eligibility criterion to receive a good cause waiver, but IPV experience does not always determine the need for good cause waivers among IPV victims (Fontana, 2000). Therefore, this paper assumes the following ordinal preferences of good cause waivers in universal screening - that a TANF applicant with IPV experience who is indifferent about receiving a good cause waiver does not disclose IPV. A full assumption of ordinal preferences for both a TANF applicant and a caseworker is presented in the next section.

Third, this paper assumes that universal screening for IPV involves two types of information: information of a TANF applicant's IPV characteristics and information about good cause waivers. On the one hand, universal screening for IPV determines the applicant's hidden IPV characteristics as a starting point. It is assumed that caseworkers should know the true state of applicants' IPV experience in order to achieve intended outcomes of granting a good cause waiver. When a game model is drawn as a figure, this characteristic is set as a starting point of the game (Matos et al., 2010); see Figure 1.

On the other hand, in universal screening for IPV, information about good cause waivers needs to be common knowledge between players. TANF applicants need to know that good cause waivers are available to them. Although it is not the case for all states and local agencies, universal screening for IPV entails universal notification of good cause waivers to TANF applicants (DeCarli, 2001; Lindhorst \& Padgett, 2005). The assumption of a rational caseworker based on quality of service may eliminate information asymmetry of available strategies for IPV victims. In this case, caseworkers routinely inform TANF applicants of good cause waivers.

Fourth, this paper simplifies players' behavioral strategies for the informed decision of a TANF applicant to disclose IPV. This paper defines a critical tenet of universal screening for IPV as a TANF applicant's informed decision to disclose IPV. If the universal screening process for IPV that promotes such informed decision is deconstructed, it may entail very complex decisional points in order that: 1) a TANF applicant applies for TANF; 2) a caseworker screens for IPV; 3) a TANF applicant discloses abuse; 4) a caseworker informs 
a TANF applicant of good cause waivers; 5) a TANF applicant who did not disclose IPV may disclose IPV after being informed of good cause waivers and continue to other decisional points. Contingent upon the informed decision to disclose IPV, this paper focuses only on two key decision points: TANF applicant's disclosure of IPV, disclose or not disclose, and TANF caseworkers granting of good cause waivers, grant a waiver or not grant a waiver.

Additionally, this paper also limits this conceptualization of universal screening for IPV with a couple of supplementary assumptions to rationalize the relevance between the theory and the phenomenon of universal screening for IPV. This paper excludes the possibility of a third person such as a domestic violence specialist. Also, this paper does not account for the possibility of repeated games or prior experience with the game by the players.

\section{Informed IPV Disclosure and Applicants' Utility of Good Cause Waivers}

The model of universal screening that supports the informed decision to disclose IPV is depicted in Figure 1. Figure 1 shows a Bayesian strategic game model with incomplete information. The strategy profiles are all valid: disclose or not disclose for the applicants and grant a waiver or not grant a waiver for eligibility caseworkers. "N" determines the applicant's state of IPV: applicants with IPV experience $\left(\omega_{1}\right)$ with probability $p$ or applicants without IPV experience $\left(\omega_{2}\right)$ with probability 1- $p$. When applicants disclose IPV, caseworkers will either grant or not grant a waiver with a probability of $q$ if they believe applicants to be victims of IPV $\left(\omega_{1}\right)$, and with a probability of 1-q if caseworkers believe applicants have not experienced IPV $\left(\omega_{2}\right)$. Reversely, caseworkers will take no action when the applicant chooses not to disclose, so they unnecessarily set a conditional belief about the IPV state $\left(\omega_{1}\right.$ or $\left.\omega_{2}\right)$.

Figure 1 also presents the expected utilities for TANF applicants that the model assigns. If a caseworker grants a waiver, then the applicant's expected utility is 1 , being granted a waiver. Receiving a waiver may benefit applicants without IPV experience $\left(\omega_{2}\right)$ if they intentionally misinform. Applicants' disclosure, therefore, could be based on need or fraud. Both types of applicants who do not disclose IPV may be indifferent to receiving a waiver, so they do not disclose abuse (0 represents those who do not disclose abuse). The model assumes that informed disclosure, compared with informed non-disclosure, is more likely to increase applicants' expected utility of receiving a waiver and to decrease their expected utility by the failure to receive a waiver ( -1 represents those who disclose abuse but are not granted a waiver).

Caseworkers have three types of expected utilities according to the assumption of rationality: 1 when caseworkers make the right decision regarding the state of IPV, 0 when caseworkers do not grant a waiver to an applicant either with IPV experience $\left(\omega_{1}\right)$ or without IPV experience $\left(\omega_{2}\right)$ who does not disclose, and -1 when caseworkers grant a waiver to an applicant without IPV experience $\left(\omega_{2}\right)$ or do not grant a waiver to an applicant with IPV experience $\left(\omega_{1}\right)$. An expected utility of 0 for an applicant with IPV experience $\left(\omega_{1}\right)$ is considered a client's self-determination to not accept a waiver. Thus, $(1,-1)$ in the 
right, bottom node indicates an applicant's utility of receiving a waiver (1), and a caseworker's utility of granting a waiver $(-1)$.

Figure 1. Informed IPV Disclosure and Applicants' Utility of Good Cause Waivers

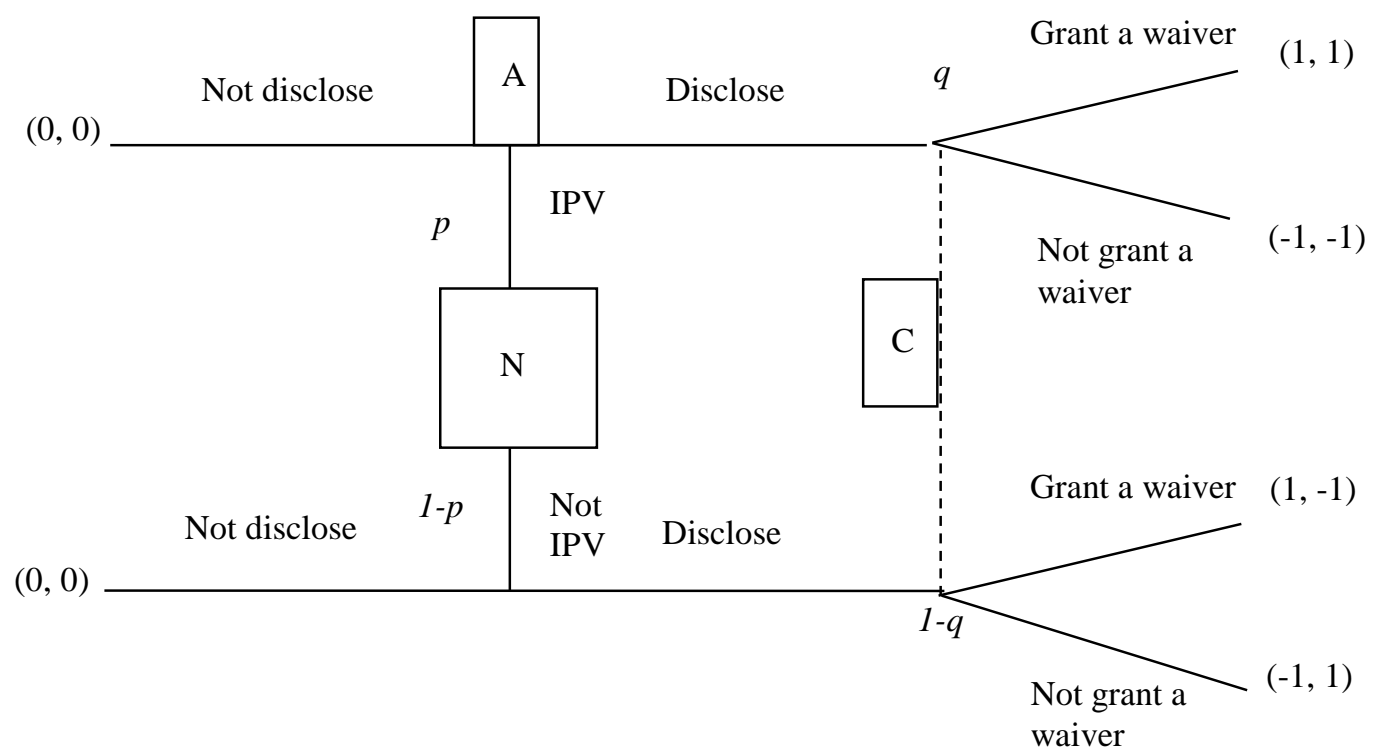

\section{Uninformed IPV Non-disclosure and the Termination of a Game}

A second model hypothesizes the situation of an uninformed decision to disclose IPV by a TANF applicant. The aim of developing such a model is to illuminate the disjuncture from universal screening for IPV. Thus, a comparison of two different scenarios of informed and uninformed decisions to disclose IPV are available. In this new scenario, a TANF applicant makes a decision to disclose IPV, given no information about good cause waivers.

Figure 2 represents the game rules of an uninformed decision to disclose IPV by TANF applicants. Under such rules, routine screening and notification of good cause do not guide TANF applicants' disclosure of IPV. Informed disclosure of IPV is strictly unavailable, making it impossible to grant a waiver because the information of a good cause waiver is asymmetrically available to caseworkers and applicants. The left side of Figure 2 from the nature $(\mathrm{N})$ shows that applicants are given a single strategy profile, not disclose, due to unavailable knowledge of good cause waivers. And, the only available strategy for the caseworker is not grant a waiver in response to the applicant's non-disclosure. The probabilities $r$ and 1-r represent a caseworker's belief about the states of IPV, given an applicant's action, not disclose. Such uninformed non-disclosure is a distinctive feature of the uninformed decision to disclose IPV, which is inconsistent with universal screening for 
IPV. This uninformed non-disclosure is different from informed non-disclosure, which is based on applicants' self-determination in the left nodes in Figure 1. Uninformed nondisclosure is caused by the IPV screening process eliminating applicants' strategies because the IPV screening process does not entail notification of good cause waivers.

Figure 2. Uninformed IPV Non-disclosure and the Termination of a Game

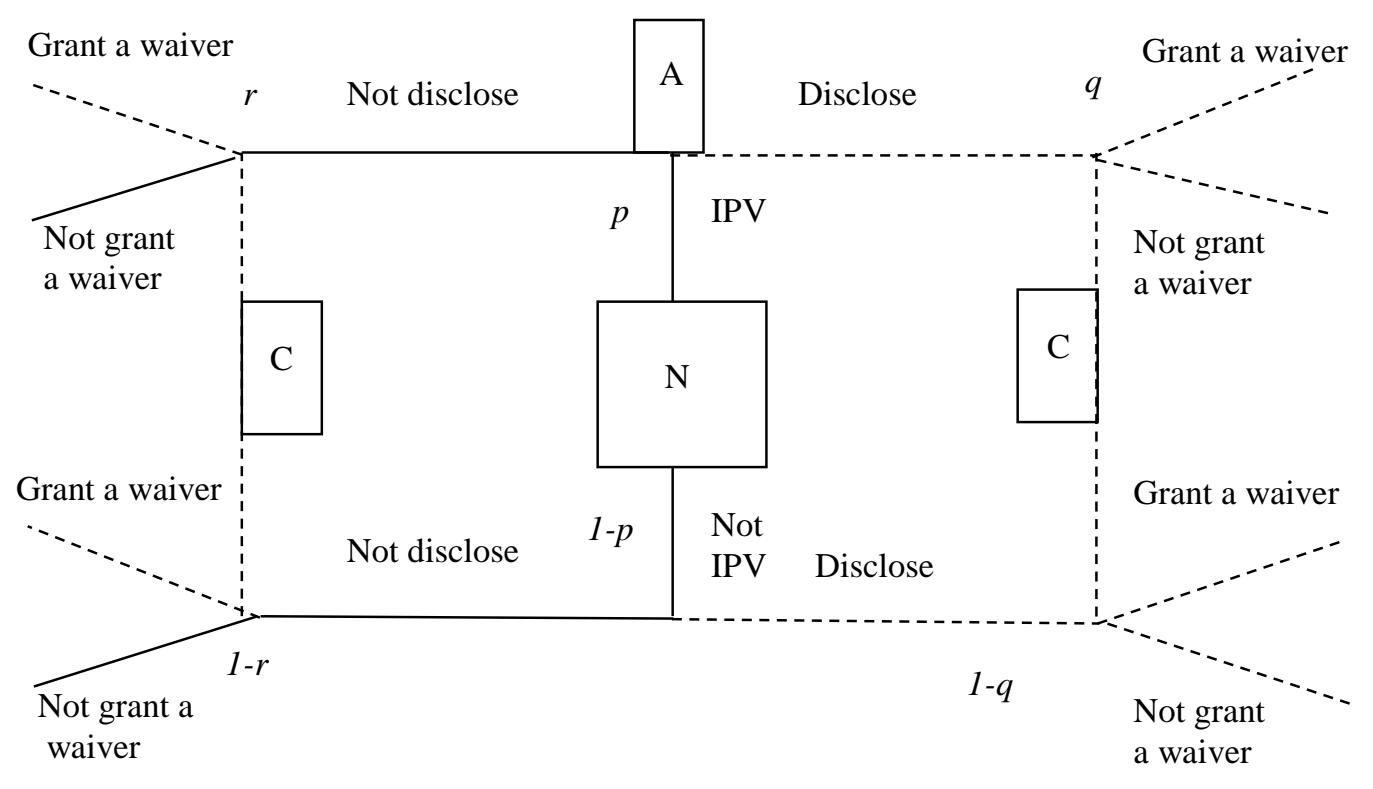

Notification of good cause waivers influences the players' expected utilities, but that effect cannot be displayed with numerical expected utilities in the model. When the players have the single strategy profile not disclose and not grant a waiver, the interaction does not satisfy game assumptions. This type of game rule does not transfer expected rewards to the applicants who experience IPV.

\section{Outcomes of the Game Models}

This section finds Nash Equilibrium, which is a decisional outcome (Osborne \& Rubinstein, 1994) from the model of the Informed IPV Disclosure and Applicants' Utility of Good Cause Waivers depicted in Figure 1. Nash Equilibrium is a steady state where both players have no reason to change their strategy (Osborne, 2004). Any found equilibriums indicate predicted outcomes specifically regarding the granting of a waiver as the final outcome in this specific model.

To find the equilibriums, the model of Informed IPV Disclosure and Applicants' Utility of Good Cause Waivers was reviewed with four different sub-games. The subgames consist of two separate games and two pooling games. These sub-games are characterized by two types of assumptions regarding (1) the caseworkers' beliefs of an applicant's types in IPV experience $\left(\omega_{1}\right.$ or $\left.\omega_{2}\right)$ and (2) the applicants' potential behaviors, 
disclose or not disclose. Regarding the applicants' potential behaviors, a separating game is where the first player behaves differently prior to the second player's strategy (MunozGarcia, 2012), meaning that a caseworker thinks that an applicant behaves inconsistently but has behaved consistently with the states of IPV. In the model, two separate games are played by a TANF applicant: 1) when there is a possibility an applicant with IPV experience $\left(\omega_{1}\right)$ discloses while an applicant without IPV experience $\left(\omega_{2}\right)$ does not disclose (see the right, upper node and the right, bottom node in Figure 1) and 2) when there is a possibility an applicant with IPV experience $\left(\omega_{1}\right)$ does not disclose while an applicant without IPV experience $\left(\omega_{2}\right)$ discloses (see the right, upper node and the left, bottom nodes in Figure 1)

A pooling game is played when the first player consistently chooses a strategy (MunozGarcia, 2012). Two pooling games are played in the model in Figure 1: 1) when there is a possibility that an applicant with IPV experience $\left(\omega_{1}\right)$ and also an applicant without IPV experience $\left(\omega_{2}\right)$ discloses (see the upper right and bottom right nodes) and 2) when there is a possibility that both types of applicants do not disclose (see the upper left and bottom left nodes).

Regarding the beliefs of eligibility caseworkers, the first separating subgame assumes a caseworker believes only an applicant with IPV experience will disclose $(q=1)$. The second separating subgame assumes a caseworker believes only an applicant without IPV will disclose $(q=0)$. The first pooling game assumes that a TANF caseworker believes both applicants with and without IPV experience will disclose $(q=p)$. Thus, a caseworker believes an applicant with IPV experience is more likely to disclose than applicants without IPV experience $(q \geq 1-q)$. In the second pooling game, a caseworker believes that all types of applicants will not disclose IPV.

Screening outcomes of the game model called Informed Decision to Disclose IPV in Universal Screening were analyzed based on the utilities in numbers (i.e., 1, 0, -1) in Figure 1. The game that is described in Figure 1 helps understand the logical process to find the equilibriums. There was no predicted outcome (equilibriums) in either separating games in Figure 1. In the first separating game, granting a waiver is an optimal strategy for caseworkers because they think an applicant with IPV experience $\left(\omega_{1}\right)$ would disclose. An applicant with IPV experience $\left(\omega_{1}\right)$ would be better off by disclosing (expected utility, 1) than by not disclosing (expected utility, 0). Because a caseworker would grant a waiver if an applicant disclosed regardless of the state of IPV ( $q=1)$, an applicant without IPV experience $\left(\omega_{2}\right)$ would also be better off by disclosing than by not disclosing. An applicant without IPV experience $\left(\omega_{2}\right)$ would also prefer to alter her strategy from not disclose to disclose. Therefore, no equilibrium can exist for this separating game.

In the second separating game, caseworkers' optimal strategy is not granting a waiver if they think that an applicant without IPV experience $\left(\omega_{2}\right)$ discloses. In that case, an applicant with the state of $\omega_{2}$ would not disclose IPV because she is not granted a waiver. Hence, an applicant without IPV experience $\left(\omega_{2}\right)$ would prefer not to disclose because the applicant's strategy of not disclose has a higher expected utility than that of disclose (expected utility, $0>$ expected utility, -1 ). Therefore, there is no equilibrium. 
The first pooling game embraces two different conditional beliefs of applicants' types and the behaviors. When a caseworker believes an applicant with IPV experience is less likely to disclose than is an applicant without IPV experience, caseworkers must select not granting a waiver because they think that the applicant is more likely to be an applicant without IPV experience $\left(\omega_{2}\right)$ than an applicant with IPV experience $\left(\omega_{1}\right)$. If a caseworker prefers not granting a waiver, the expected utility of an applicant without IPV experience $\left(\omega_{2}\right)$ would be -1. Consequently, this applicant would prefer to not disclose IPV (expected utility, 0), which entails a higher expected utility, rather than disclose (expected utility, 1). Therefore, with this specific belief, there is no equilibrium.

Conversely, if a caseworker believes an applicant with IPV experience is more likely to disclose than an applicant without IPV experience is, a caseworker optimally selects granting a waiver. Given a caseworker's strategy, granting a waiver, applicants may also perceive the higher expected utility 1 compared to -1 if they are not granted a waiver. Thus, applicants, regardless of experience with IPV, will disclose if they believe that they are more likely to be granted a waiver rather than being denied. Thus, an equilibrium occurs if a caseworker believes a disclosed applicant is a real victim and the applicant believes a waiver will be granted by disclosure.

In the second pooling game, notice that both types of applicants prefer to not disclose (payoff 0) only if caseworkers select to not grant a waiver. The strategy, not disclose, contains a higher payoff compared to the situation where an applicant discloses but is not granted a waiver (expected utility -1 ; see the right nodes in Figure 1). In order for not granting a waiver to be chosen, a caseworker must have a sufficiently pessimistic belief about the types of applicants despite their strategy for IPV disclosure. Regardless of the states of IPV, a caseworker believes an applicant without IPV experience $\left(\omega_{2}\right)$ is more likely to disclose than an applicant with IPV experience $\left(\omega_{1}\right)$. Within such belief systems, an applicant would prefer to not disclose as this sub-game predisposes. Thus, a caseworker's strategy, not granting a waiver, is optimal. In the second pooling game, an equilibrium exists when a caseworker believes that a disclosed applicant is not the real victim and an applicant regardless of IPV experience believes that they would not be granted a waiver.

Two equilibriums were found in the model of Informed Decision to Disclose IPV in Universal Screening. That is, two outcomes are predicted if universal screening for IPV is implemented as assumed. The first outcome is applicants disclose IPV experience and caseworkers grant a waiver when caseworkers believe disclosed applicants are real victims and applicants believe they will be granted a waiver by disclosure. The second outcome is applicants do not disclose IPV and caseworkers do not grant a waiver when caseworkers believe that disclosed applicants are not the real victims and applicants regardless of IPV experience believe that they would not be granted a waiver.

Figure 2 describes the scenario of Uninformed Decision to Disclose. The model of the no knowledge situation of good cause waivers cannot assign expected utilities to the players' strategy profiles. Allowing both an applicant and a caseworker to play a single strategy results in the play of not disclose by an applicant and not grant a waiver by a 
caseworker. Such strategy set clarifies that screening outcomes possess disjuncture from universal screening for IPV.

\section{Discussion and Limitations}

This paper claims that the intended outcomes of universal screening for IPV-granting of a good cause waiver to victims of IPV-are difficult to achieve without accurate IPV screening. Two game models, particularly using a Bayesian strategic game model of universal screening for IPV in TANF, helped explore the underlying assumptions of universal screening for IPV to achieve the intended outcomes of granting good cause waivers to IPV victims. The models also helped explore different strategies and outcomes based on whether or not a TANF applicant makes an informed decision to disclose abuse. Development of such models is useful in 1) generating potential hypotheses for empirical tests, and 2) exploring assumptions of universal screening for IPV by refining the original components and assumptions of game theory, especially the rationality assumption for TANF frontline eligibility caseworkers.

This paper suggests a need of empirical testing of several hypotheses as well as measurement development. Equilibriums from the informed decision model for IPV disclosure in Figure 1 suggest two hypotheses: 1 ) a good cause waiver is given to a TANF applicant only when the TANF applicant discloses IPV experience to a TANF caseworker who tends not to worry about potential fraud from TANF applicants, and 2) a good cause waiver is not given to a TANF applicant who does not disclose IPV if a caseworker believes that only a small number of TANF applicants are victims of IPV. In addition, from the uninformed decision model for IPV, 3) non-disclosure is a hypothetical outcome when a TANF applicant is not informed of a good cause waiver by a caseworker. The two models also illuminate crucial concepts that could be included as variables in quantitative research questions and/or could be measured for future policy evaluation. Valid and reliable measurement of such concepts is essential. Future studies could define and operationalize constructs of such variables in more valid and reliable ways. Such variables include the TANF applicant's need for a good cause waiver, the caseworker's belief of TANF applicants' need for a good cause waiver and their state of IPV, and universal screening for IPV. For example, the informed decision to disclose IPV may be facilitated with a combination of routine screening and routine notification of a good cause waiver. However, without measuring and including variables of both behaviors in a statistical model for testing, we cannot know the real preferences of behaviors or strategies of TANF applicants regarding a good cause waiver.

Several assumptions to conceptualize universal screening for IPV in the Bayesian strategic game model imply that equilibriums may exist only based on the accuracy of IPV screening. Both the rationality assumption and information about a good cause waiver available to TANF applicants may be relevant constructs of the quality of IPV screening. According to the rationality assumption, caseworkers' preferences for granting a waiver are determined by accountable implementation of IPV screening. Caseworkers prefer to respond accurately to an applicant's state of IPV in granting a good cause waiver. The model of universal screening for IPV also identified information of a good cause waiver that may remove uncertainty for a TANF applicant to strategically disclose IPV to a 
caseworker. In order to employ universal screening for IPV, caseworkers should also routinely provide information of good cause waivers to TANF applicants.

The rationality assumption for TANF caseworkers also invites potential applicability of anti-rationality assumptions to understand TANF caseworkers' behaviors for future research. In the model of universal screening for IPV, the caseworker's motive for choosing a strategy was supposed to be driven by their role, not their personal instincts, preconceptions, attitudes, etc. Such an assumption is not aligned with the original rationality assumption of game theory. This approach is not uncommon in the study of human behaviors. Outside formal game theory, human behaviors are considered irrational with alternative assumptions, such as bounded rationality, framing effects, and/or risk adversity (Simon, 2001; Tversky \& Kahneman, 1982, 1986). Human beings sometimes act upon altruism, fairness, and/or trust rather than self-interest (Thaler, 1991). This paper attempted to apply game theoretical concepts in model development of universal screening for IPV, but the rationality assumption of the model actually emphasized the role of TANF caseworkers who may be fair and altruistic.

Two conditions of universal screening for IPV--routine screening of IPV and routine notification of a good cause waiver--seem to require high work ethics of TANF caseworkers, relevant knowledge and skills, and person-oriented work. Such requirements together underscore the role of caseworkers in facilitating informed decision-making opportunities for TANF applicants. Such assumptions may not be realistic though, like IPV screening that is not universally implemented in the real world. We simply notice the similarity from evidence of IPV screening in TANF and agree with the claim that it is difficult to expect street-level bureaucrats to do people-oriented work to enhance clients' self-determination (Lipsky, 1969; Watkins-Hayes, 2009). This paper cannot conclude whether IPV screening in TANF is an implementation failure or policy design failure, but it is noteworthy that the policy design appears to embrace unrealistic expectations for the frontline worker to implement the expected rules.

A Bayesian strategic game model in formalizing models of a TANF applicantcaseworker interaction in TANF, however, cannot help in understanding "why actors are not contributing" to achieve intended outcomes or how unintended outcomes may result from interactions (Hermans et al., 2014, p. 12). As discussed, game theory may offer insights on predictors of observed outcomes. However, it does not offer a tool to identify reasons for not granting a waiver or specific barriers to granting a good cause waiver. The authors strongly believe that research on the barriers to employing universal screening for IPV would be quite valuable for presenting evidence of how to improve IPV screening in TANF. However, game theory and the models discussed in this paper are not the proper tools to determine how to solve the problem of universal screening for IPV not working in the real world (Schelling, 2010).

In addition, overcoming the following shortcomings may strengthen the models presented in this paper as an evaluation method. First, the applicant's experience with IPV is not identical to the need to utilize a waiver. This paper considers them equal. Future study can make this distinction and investigate who among applicants with IPV experience actually needs a waiver. Second, the model of universal screening does not undergo all the 
possible steps related to game rules that could actually establish the applicants' expected utilities differentially. The rationales for determining expected utilities need to be set clearly. Third, this paper does not test the models and their hypotheses, so future studies need to analyze empirical data to investigate whether good cause notification determines the use of a waiver.

Despite such limitations, this paper's application of the Bayesian strategic game model was beneficial to exemplify game theory as an alternative tool in evaluating the FVO at the level of actor-interactions. This paper also revealed the potential use of soft application of game theory in policy evaluations rather than mathematical application of the theory.

\section{References}

Agee, M. D., \& Gates, Z. (2013). Lessons from game theory about healthcare system price inflation: Evidence from a community-level case study. Applied Health Economics and Health Policy, 11(1), 45-51. doi: http://dx.doi.org/10.1007/s40258$\underline{012-0003-\mathrm{Z}}$

Akerlof, G. A. (1970). The marker for “lemons:” Quality uncertainty and the market mechanism. Quarterly Journal of Economics, 84(3), 488-500. doi: http://dx.doi.org/10.2307/1879431

Barnett II, W. (2003). The modern theory of consumer behavior: Ordinal or cardinal? The Quarterly Journal of Austrian Economics, 6(1), 41-65. doi: http://dx.doi.org/10.1007/s12113-003-1012-4

Brush, L. D. (2004). Battering and the poverty trap. Journal of Poverty, 8(3), 23-43. doi: http://dx.doi.org/10.1300/J134v08n03_02

California Department of Social Services Data Systems and Survey Design Bureau. (2013, February 11). CalWORKs Welfare-to-work monthly activity report: All families. Retrieved from http://www.cdss.ca.gov/research/res/pdf/WTW25/2012/WTW25Dec12.pdf

Carrington, K. (2005). Street-level discretion: Is there a need for control? Public Administration Quarterly, 29, 141-162.

Casey, T. (2010). The sanction epidemic in the Temporary Assistance for Needy Families. Retrieved from http://www.legalmomentum.org/resources/tanf-sanctionsharm-the.html

Casey, T., Davies, J., Gifford, A., \& Menard, A. (2010). Not enough: What TANF offers family violence victims. New York, NY: Legal Momentum and Harrisburg, PA: National Resource Center on Domestic Violence.

Cooke, J., \& Burke, V. (2003, January). CRS report for Congress: Welfare law and domestic violence. Retrieved from http://www.policyarchive.org/handle/10207/bitstreams/3384.pdf

Davies, J. (2010, March). Family violence protocol development. Retrieved from http://www.mincava.umn.edu/documents/welprac2/welprac2.html 
DeCarli, J. (2001, January). Statistics on New York's Family Violence Option reflect poor implementation. New York, NY: Empire Justice Center. Retrieved from http://www.empirejustice.org/issue-areas/domestic-violence/public-benefitsdomestic-violence/statistics-on-new-yorks-family-violence-option.html

Dowd, B. E. (1982). The logic of moral hazard: A game theoretic illustration. Journal of Risk \& Insurance, 49(3), 443-447. doi: http://dx.doi.org/10.2307/252498

Field, A. J. (2014). Schelling, von Neumann, and the event that didn't occur. Games, 5(1), 53-89. doi: http://dx.doi.org/10.3390/g5010053

Fontana, J. M. (2000). Cooperation and good cause: Greater sanctions and the failure to account for domestic violence. Wisconsin Women's Law Journal, 15, 367-391.

Gallagher, R. J. (2011). Welfare reform's inadequate implementation of the FVO. American University Journal of Gender, Social Policy \& the Law, 19, 987-1008.

Garratt, R. J., Troger, \& Zheng, C. Z. (2009). Collusion via resale. Econometrica, 77(4), 1095-1136. doi: http://dx.doi.org/10.3982/ECTA7504

Giocoli, N. (2006). Do prudent agents play lotteries? von Neumann's contribution to the theory of rational behavior. Journal of the History of Economic Thought, 28(1), 95-109. doi: http://dx.doi.org/10.1080/10427710500509714

Government Accountability Office. (2005). TANF: State approaches to screening for intimate partner violence could benefit from HHS guidance. Washington, DC: U.S. Government Printing Office. Retrieved from http://www.gao.gov/new.items/d05701.pdf

Greif, A. (2006). Institutions and the path to the modern economy: Lessons from medieval trade. New York: Cambridge University Press.

Groseclose, T., \& Milyo, J. (2013). Sincere versus sophisticated voting when legislators vote sequentially. Social Choice \& Welfare, 40(3), 745-751. doi: http://dx.doi.org/10.1007/s00355-011-0639-x

Harsanyi, J. C. (1987). Games with incomplete information played by "Bayesian” players. Management Science, 50(12), 1804-1817.

Hearn, M. (2000). Dangerous indifference: New York City's failure to implement the FVO. New York, NY: NOW Legal Defense and Education Fund, Legal Aid Society, Women, Welfare and Abuse Task Force, and Urban Justice Center.

Hermans, L., Cunningham, S., \& Slinger, J. (2014). The usefulness of game theory as a method for policy evaluation. Evaluation, 20(1), 10-25. doi: http://dx.doi.org/10.1177/1356389013516052

Hetling, A. H. (2011). Welfare caseworker assessments and intimate partner violence services. Violence Against Women, 17(8), 1046-1066.

doi: http://dx.doi.org/10.1177/1077801211414928 
Hetling, A. H., \& Born, C. E. (2006). Specialists in welfare offices: Do family violence experts matter? Administration in Social Work, 30(4), 19-36.

doi: http://dx.doi.org/10.1300/J147v30n04_03

Keeney, R. L., \& Nau, R. (2011). A theorem for Bayesian group decisions. Journal of Risk and Uncertainty, 43, 1-17. doi: http://dx.doi.org/10.1007/s11166-011-9121-5

Lawrence, S. (2002). Intimate partner violence and welfare policy: Research findings that can inform policies on marriage and child well-being. New York, NY: National Center for Children in Poverty.

Levin, C. F., \& Zeisel, K. (2009). Shortchanging survivors: The Family Violence Option for TANF benefits. Washington, DC: National Law Center on Homelessness \& Poverty. Retrieved from http://www.nlchp.org/content/pubs/Shortchanging_Survivors_Report 20092.pd $\underline{\mathrm{f}}$

Levin, R. (2001). Less than ideal: The reality of implementing a welfare-to-work program for domestic violence victims and survivors in collaboration with the TANF department. Violence Against Women, 7, 211-221. doi: http://dx.doi.org/10.1177/10778010122182406

Lindhorst, T., Casey, E., \& Meyers, M. (2010). Frontline worker responses to intimate partner violence disclosure in public welfare offices. Social Work, 55(3), 235-243. doi: http://dx.doi.org/10.1093/sw/55.3.235

Lindhorst, T., Meyers, M., \& Casey, E. (2008). Screening for intimate partner violence in public welfare offices. Violence Against Women, 14, 5-28. doi: http://dx.doi.org/10.1177/1077801207311948

Lindhorst, T., \& Padgett, J. D. (2005). Disjuncture for women and frontline workers: Implementation of the FVO. Social Service Review, 79(3), 405-429. doi: http://dx.doi.org/10.1086/430891

Lipsky, M. (1969). Toward a theory of street-level bureaucracy. Madison, WI: The University of Wisconsin.

Matos, M. C., Ferreira, M. A., \& Andrade, M. (2010). Code form game. International Journal of Academic Research, 2(1), 135-141.

Meisel, J., Chandler, D., \& Rienzi, B. M. (2003). IPV prevalence and effects on employment in two California TANF populations. Violence Against Women, 9, 11911212. doi: http://dx.doi.org/10.1177/1077801203255861

Meyers, M. K., \& Laurie, I. (2005, June). The decline in welfare caseloads: An organizational perspective. Paper presented at the Mixed Methods Research on Economic Conditions, Public Policy, and Family and Child Well-Being, Ann Arbor, MI. 
Miller, G. J., \& Whitford, A. B. (2002). Trust and incentives in principal-agent negotiations: the "insurance/incentive trade-off." Journal of Theoretical Politics, 14, 231-267. doi: http://dx.doi.org/10.1177/095169280201400204

Milton, C. L. (2006). Breaking the rules of the game: Ethical implications for nursing practice and education. Nursing Science Quarterly, 19(3), 207-210. doi: http://dx.doi.org/10.1177/0894318406289442

Moe, T. M. (1984). The new economics of organization. American Journal of Political Science, 28(4), 739-777. doi: http://dx.doi.org/10.2307/2110997

Munoz-Garcia, F. (2012). A systematic procedure for finding perfect Bayesian equilibria in incomplete information games. Journal of Industrial Organization Education, 6(1), 1-23. doi: http://dx.doi.org/10.1515/1935-5041.1049

National Association of Social Workers [NASW]. (2008). Code of ethics. Retrieved from http://www.socialworkers.org/pubs/code/default.asp

NASW. (2013). New standards for social work management. Retrieved from http://www.socialworkers.org/practice/naswstandards/CaseManagementStandar ds2013.pdf

Nelson, H. D., Nygren, P., Mclnerney, Y., \& Klein, J. (2013). Screening for women and elderly adults for family and IPV: Review of the evidence. Retrieved from http://uspreventiveservicestaskforce.org/3rduspstf/famviolence/familyviolrev.htm

Norris, J., Speiglman, R., \& Dasinger, L. (2002). San Joaquin County CalWORKs needs assessment and outcomes study: Health and other potential barriers to working and self-sufficiency. Berkeley, CA: Public Health Institute.

Nurmi, P. (2005). Bayesian game theory in practice. Finland: University of Helsinki.

Osborne, M. J. (2004). An introduction to game theory. New York, NY: Oxford University Press.

Osborne, M. J., \& Rubinstein, A. (1994). A course in game theory. Cambridge, MA: MIT Press.

Pataki, G. E., \& Doar, R. (2006, March). New York State Office of Temporary and Disability Assistance. Retrieved from http://otda.ny.gov/policy/directives/2006/INF/06-INF-11.pdf

Polachek, S., \& Xiang, J. (2010). How opportunity costs decrease the probability of war in an incomplete information game. International Organization, 64(1), 133-144. doi: http://dx.doi.org/10.1017/S002081830999018X

Raphael, J., \& Haennicke, S. (1999). Keeping battered women safe through the welfareto-work journey: How are we doing? Chicago, IL: Center for Impact Research.

Saam, N. J. (2007). Asymmetry in information versus asymmetry in power: Implicit assumptions of agency theory? The Journal of Socio-Economics, 36, 825-840. doi: $\underline{\text { http://dx.doi.org/10.1016/j.socec.2007.01.018 }}$ 
Savage, L. J. (1954). The foundations of statistics. New York, NY: John Wiley Sons.

Schelling, T. C. (2010). Game theory: A practitioner's approach. Economics and Philosophy, 26(1), 27-46. doi: http://dx.doi.org/10.1017/S0266267110000040

Shepsle, K. A. (Ed.). (2010). Analyzing politics: Rationality, behavior, and institutions. New York, NY: W.W. Norton \& Company.

Simon, H. A. (2001). On simulating Simon: His monomania, and its sources in bounded rationality. Studies in the History and Philosophy of Science, 32, 501-505. doi: http://dx.doi.org/10.1016/S0039-3681(01)00013-9

Spatz, D., Katz, S., \& Rees, A. (2005, June). Family violence is not an option. The failure of CalWORKs to protect battered women with children. Retrieved from http://www.geds-tophds.org/Approved\%20to\%20post\%20on\%20website/FVNO\%20Final\%2010.05.pdf

Speiglman, R., Fujiwara, L., Norris, J., \& Green, R. S. (1999). Alameda County CalWORKs needs assessment: A look at potential health-related barriers to selfsufficiency. Berkeley: Public Health Institute.

Thaler, R. H. (1991). Quasi rational economics. New York, NY: Russell Sage Foundation.

Tolman, R. M., \& Rosen, D. (2001). Intimate partner violence in the lives of women receiving welfare. Violence Against Women, 7, 141-158. doi: http://dx.doi.org/10.1177/1077801201007002003

Tversky, A., \& Kahneman, D. (1982). Judgment under uncertainty: Heuristics and biases. In D. Kahneman, P. Slovic, \& A. Tversky (Eds.), Judgment under uncertainty: Heuristics and biases (pp. 3-20). Cambridge: Cambridge University Press.

Tversky, A., \& Kahneman, D. (1986). Rational choice and the framing of decisions. The Journal of Business, 59, S251-S278. doi: http://dx.doi.org/10.1086/296365

von Neumann, J., \& Morgenstern, O. (1953). Theory of games and economic behavior. Princeton, NJ: Princeton University Press.

Watkins-Hayes, C. (2009). The new welfare bureaucrats: Entanglements of race, class, and policy reform. Chicago, IL: University of Chicago Press.

Witzel, A. (2009). Knowledge and games: Theory and implementation. Santa Fe, Amsterdam: Institute for Logic, Language, and Computation.

Zamir, S. (2010, June). Bayesian games: Games with incomplete information. Retrieved from http://www.ma.huji.ac.il/ zamir/documents/BayesianGames_ShmuelZamir.pdf

\section{Acknowledgement}

This article is adapted from a dissertation funded by the Fahs-Beck Fund for Research and Experimentation, Doctoral Dissertation Grants, New York Community Trust.

\section{Author note}


Address correspondence to: Soonok An, PhD, School of Social Work, University of Georgia, 279 Williams Street, Athens, GA 30602-7016, Phone: (706) 424-1470 / Fax: (706) 542-3364 /Email: aso@uga.edu 